\title{
An Analysis of Fertility Change in Pakistan
}

\section{NASEem IQbal Farooqui and GHUlam YASIN SOOMRO*}

\section{INTRODUCTION}

In most of the developing countries, sustained population growth rates have been a dominant factor in decelerating socio-economic development. The continuing decline in mortality rates has been a major contributor to the acceleration of growth of population in these countries which started in the period following the second World War, and has not abated yet in most of the developing world. There is every likelihood that the population of these developing countries will double in the course of the next generation or so, because of the demographic momentum that is built into their age structure. The rapidly increasing population in low-income countries is not keeping pace with the necessary cultural and technological changes that may help them to raise the standard of living of their masses. Also, high rates of population growth have become a barrier to a successful attainment of the desired socioeconomic development, both quantitative and qualitative.

Like other developing countries, Pakistan also faces a population problem. The trends of population growth observed for the 50 years prior to 1951 (i.e. the 1901-1951 period) indicate that the growth rate in the area constituting Pakistan was then closer to 1 percent per annum. During the next 30 years $(1951-81)$ the population growth rate was, however, closer to 3 percent per annum $[6 ; 7 ; 8 ; 9$; 10]. This observed increase in population growth rates in the last 30 years (1951-1981) was largely attributed to the decline in mortality levels. The female population of reproductive ages has been growing because of the fertility potential of the previous cohorts as well as the decline in maternal mortality. The increase in the number of women in reproductive ages consequently means more births and additional strain on the resources of the country. The proportion of population aged less than 15 years remains static at roughly 45 percent, creating multidimensional problems of food and nutrition, health, education, employment, etc.

A little decline was, however, observed in fertility levels. This decline was caused by changes in nuptiality patterns, the introduction of family planning during

*Research Demographers, Pakistan Institute of Development Economics, Islamabad (Pakistan) 
the Third Five Year Plan (1965-70) and continuing socio-economic development. The objective of this study is, therefore, to assess the contribution of various demographic and socio-economic factors to fertility change in Pakistan for the period from 1965 to 1978. An attempt has also been made to measure the impact of family planning programme efforts on fertility levels by the year 1978 .

\section{DATA AND METHODOLOGY}

For decomposing changes in fertility rates between two periods in time, the data selected were those of PGE $^{1}$ [2] and PGS (Phase II) [11]. Since age of mother at the time of enumeration or registration of live births was not asked for the PGE year, 1962, only the data relating to the years 1963 through 1965 were utilized for the present study.

The live births reported by the two surveys under observation had been estimated for each sample area through the matching procedure and aggregated at the national level. Comprehensive matching procedures adopted by the PGE and its analytical results are all well documented [2]. However, the presumed matching procedures and their analytical results as claimed by PGS [11] have not been documented so far. One criticism that can be levelled against the PGE estimates of vital events is that, owing to exhaustive matching procedures, vital events were overestimated for the $\mathrm{CD}$ categories, whereas no such matching operation was undertaken in the case of base population. The main problem with the PGE estimates was that as in all other surveys the quality of enumeration tended to deteriorate with the passage of time. The 1965 war with India, further aggravated this situation. Therefore, the average of the 1962-65 rates is bound to represent an underestimate of the true rates. The usual problems of age reporting and sampling and non-sampling errors are present in both the data sets under observation.

The programme service statistics utilized in this study also suffer from various types of errors. The major limitation of this data set is its doubtful reliability. This problem arises in a situation where workers are required to achieve targets within a specified period of time. In order to determine the contribution of various factors which are likely to affect fertility changes between two points of time, the technique of decomposition analysis has been applied to changes in crude birth rate in this study [3]. In this technique, the contribution of each single factor is isolated, keeping the effects of other factors constant.

${ }^{1}$ Since official Family Planning Programme in Pakistan was launched in the year 1965, the most appropriate fertility data for the pre-programme years could be from the PGE only.

\section{ANALYSIS OF RESULTS}

The decomposition analysis thus applied, however, pertained to the difference of crude birth rates observed between the periods 1963-65 and 1976-78. For the years 1963-65, the CBR measures obtained were the average of LR and CD estimates. However, for the years 1976-78, the average based on the data of the PGS (Phase II) was utilized. The CBR figures pertaining to these periods of time were, respectively, 46.46 and 41.43 per 1000 population [Appendix Table 1]. The estimates of fertility for the $1963-65$ period could therefore be seen as conveniently representing the potential fertility of the population just prior to the establishment of the national Family Planning Porgramme in Pakistan. As in other surveys, the age structures of the population in the two surveys also suffered from the phenomenon of digital preference [12]. However, an examination of the age structures at the two surveys revealed that the age structure of the PGE population suffered more severely from age misreporting. A quasi-stable population was, therefore, generated in accordance with the procedure developed by Coale, to adjust the PGE female age structure for possible age misreporting [1]. The relevant data for the two periods under observation are provided in Appendix Table 1. Before a decomposition analysis of the data, consistency tests were carried out, which showed that the difference between the observed and the explained crude birth rates for both the periods was negligible.

Table 1 shows that marital status tends to explain the greatest proportion of change in both the general fertility rate and the crude birth rate during the period under study. The next most important contributing factor appears to be marita fertility, which is followed in importance by age structure. In terms of the percentage distribution, marital status explains 63 percent change in both GFR and CBR On the other hand, marital fertility explains 54 percent of the change in both the GFR and CBR. Moreover, age structure on the whole explains only 20 percent of such a change. Lastly, the proportion of females in the total population tends to explain the least amount (approximately 18 percent) of change in CBR. The above four factors, taken together, seem to over-explain both GFR and CBR. The total explained change due to the above four factors comes out to be about 137 percent for GFR and 155 percent for CBR. The unexplained change, which is approximately 8.853 for GFR and 2.745 for CBR, could arise in absolute terms from the interaction among the contributing factors. The interaction term, which is probably an outcome of the combination of contributing factors, was subjected to further breakdown. The adjusted contributions of the four factors to fertility change after allowing
for the contribution of interaction terms are given in Table 2. It can be observed from the table that the adjusted contribution of age structure to both the GFR and CBR has declined from 20 percent (Table 1) to 10 percent (Table 2). Similarly, the contribution of marital status declined from 63 percent (Table 1) to 47 percent 
Table 1

Contribution of Rate of Change in Age Structure, Marital Status, Marital Fertility and Proportion Female in General Fertility Rate (GFR) and Crude Birth Rate (CBR): 1963-65 to 1976-78. (Base Years $=1963-65$ )

\begin{tabular}{lccccc}
\hline \multirow{2}{*}{\begin{tabular}{l} 
Contributing \\
\multicolumn{1}{c}{ Factors }
\end{tabular}} & \multicolumn{2}{c}{ Absolute Change in } & & \multicolumn{2}{c}{ Relative Change in } \\
\cline { 2 - 3 } \cline { 6 - 7 } \multicolumn{1}{c}{ GFR } & CBR & & GFR & CBR \\
\hline Age Structure & -4.739 & -1.004 & & -20.0 & -20.0 \\
Marital Status & -14.933 & -3.163 & & -63.0 & -63.0 \\
Marital Fertility & -12.848 & -2.722 & & -54.0 & -54.0 \\
Proportion Females & - & -0.886 & & - & -17.6 \\
Explained Change & -32.520 & -7.775 & & -137.0 & -154.6 \\
Observed Change & -23.667 & -5.030 & & -100.0 & -100.0 \\
Unexplained Change & 8.853 & 2.745 & & +37.0 & +54.6 \\
\hline
\end{tabular}

(Table 2), whereas the contribution of marital fertility declined from 54 percent (Table 1) to 39 percent (Table 2). This means that the adjusted contribution of individual factors embodied almost 100 percent of the change in GFR during the period from 1963-65 to 1976-78. The unexplained change of 3 percent in the GFR could, however, be attributed to the rounding errors involved in the calculations.

As is evident from Table 1, the contributing factors over-explained the total change in CBR by about 55 percent. This over-explanation could be due to the joint effects of various combinations of contributing factors. In statistical terminology, this contribution may be termed the interaction effect. On the basis of the calculations carried out in the lower portion of Table 2, the contribution of joint effects to CBR in absolute as well relative terms has been presented. It may be observed from the table that age structure and marital status, marital status and marital fertility, age structure and marital fertility and proportion females have tended to overstate the changes in the crude birth rate. On the other hand, the combined effect of age structure, marital status and marital fertility understate the effect. The interaction effect of marital status and marital fertility turns out to be the strongest and is followed in importance by the contribution of age structure and marital status and age structure and marital fertility. The unexplained change of approximately 15 percent in CBR between 1963-65 and 1976-78 may have been due to calculation procedures involved as well as to interaction effects.




The age structure on the whole, however, was responsible for the smallest decline in fertility levels over the period under observation. One may wonder how this contribution of age structure is possible in a population where age structure is almost constant. Since the present analysis has been carried out by taking into consideration the available data from the two national sample surveys conducted after a 15-year interval, the changes in the age structure of the two surveys may merely be due to the incidence of both the sampling and non-sampling factors. As far as changes in the age structure of Pakistan's population are concerned, it may be pointed out that it is very difficult to ascertain such changes in a situation where the incidence of age misreporting is very high [12]. It may be observed that the proportion of females in the total population explains the least amount of change in CBR during the period under observation. This change was caused by the decline of the proportion of females in the total population during the 15-year period. Approximately 21 percent females were enumerated at the PGE whereas only 20 percent of females were enumerated at the PGS (Phase II). This decline appears to be a case of under-enumeration of females at the PGS which appears to be inconsistent with the declining maternal mortality in Pakistan.

The next step after the decomposition analysis was to estimate the number of births that would have been averted in 1978 by the above-mentioned three contributing factors. The assumption here is that if the 1963-65 birth rate had prevailed through 1978 , the hypothetical number of births occurring in 1978 would have been approximately 3.5 million. The actual number of births occurring in 1978 , on the basis of the current birth rate, would be around 3.1 million. Hence, the total number of births averted in 1978 would be the difference of 0.4 million between the two estimates (Table $3 \mathrm{~A}$ ). These births have, therefore, been averted as a result of the changes occurring in the four factors. The individual contribution of each of the four factors to the number of birth averted in 1978 is given in Table 3.B. As may be seen, the number of births averted in 1978 because of changes in marital fertility alone comes to 148,198 . These births are reflective of the changes in the socioeconomic development as well as of the changes in the effective use of family planning methods during the 15 -year period. In order to arrive at the net effects of both programme and non-programme factors on the number of births averted in 1978 , it becomes essential to estimate the number of the births averted by the programme methods alone. The residual obtained after deducting the programme births from the total births would, therefore, give an estimate of the births averted due to the changes in socio-economic development alone prior to 1978.

Table 3

Basic Demographic Data and Number of Births Averted in 1978 by each Contributing Factor of Change

Basic Demographic Data

A. 1963-65 CBR

Hypothetical CBR 1976-78

Observed CBR 1976-78

Hypothetical Births Occurred during 1978

Actual Births Occurred during 1978

Births Averted during 1978
Total Population in 1978

$\begin{aligned}= & 46.50 \\ = & 46.50 \\ = & 41.43 \\ = & 75,757,673 \\ = & 3,476,232 \\ = & 3,097,210 \\ = & 379,022\end{aligned}$

B.

Births Averted by Each Factor

\begin{tabular}{lccc}
\hline $\begin{array}{l}\text { Contributing } \\
\text { Factor }\end{array}$ & $\begin{array}{c}\text { Adjusted } \\
\text { Change }\end{array}$ & $\begin{array}{c}\text { Relative } \\
\text { Change }\end{array}$ & $\begin{array}{c}\text { Births } \\
\text { Averted }\end{array}$ \\
\hline Age Structure & -0.515 & -10.3 & -39039 \\
Marital Status & -2.378 & -47.3 & -179277 \\
Marital Fertility & -1.969 & -39.1 & -148198 \\
Proportion Females & -0.886 & -17.6 & -66708 \\
Interaction & 0.718 & 14.3 & +54200 \\
\hline
\end{tabular}

\section{IMPACT OF FAMILY PLANNING PROGRAMME ON FERTILITY}

The number of births averted by the programme efforts was estimated through the use of family planning service statistics [10]. The number of births averted in 1978 was thus the result of an effective use of contraception between April 1, 1977 and April 1, 1978. The number of births averted by each programme method is given in Table 4. The total number of births averted in 1978 was, therefore, estimated at approximately 253,099 . The IUDs and conventional contraceptive methods contributed more (55 and 33 percent respectively) to the total number of the births averted. The least contribution (of around 12 percent) was attributable to the use of oral pills.

The comparison of the births averted by programme methods with those averted by marital fertility shows that the programme averted more births than were observed. Although changes in marital fertility were influenced by both programme and non-programme factors, but if it could be assumed that the births averted due to changes in marital fertility were influenced by programme factors alone, then it would appear that the contribution of the programme efforts to the number of births averted is overestimated by approximately 41 percent. 
Table 4

Number of Acceptors and Births Averted by each Method as of October 1, 1977

\begin{tabular}{lcc}
\hline Methods & Acceptors & Births Averted in 1978 \\
\hline Conventional Contraceptives (1977) & 360,000 & 119,520 \\
Oral Pills (1977) & 126,964 & 42,152 \\
IUDs (1973-77) & 275,384 & 91,427 \\
Total & 762,348 & 253,099 \\
\hline
\end{tabular}

(a) Number of acceptors was arrived at by the following programme formula: One IUD insertion = One Acceptor Thirteen cycles of pills $=$ One Acceptor

One hundred conventional contraceptive units = One Acceptor

(b) Effective users were estimated by applying the continuation rate of 0.6 for oral pills and 0.5 for conventional methods. The IUD acceptors were cumulated for the last five years $(1973-77)$ and continuation rate was calculated through decay curve, $R(t)=a e^{-r t}$ where $\mathrm{R}=$ retention rate, $\mathrm{a}=$ constant for immediate termination, $\mathrm{e}=$ natural logarithm base, $\mathrm{r}=$ constant rate of annual decline and $\mathrm{t}=$ time. The retention rates applied here were derived by life-table approach of Mauldin.

The rates applied were 0.72265 ( 4.5 months), 0.50152 (15 months), 0.33176 (27 months), 0.21903 (39 months) and 0.14461 (51 months).

(c) The age shifting of the acceptors (Q) of $i$ th age at time ' $\mathrm{t}$ ' from 1973 to 1977 was calculated by: $Q_{i, t}=a q_{i, t-1}+b q_{i-1, t-1}+c q_{i, t-2}+d q_{i-1, t-2}+e q_{i, t-3,}+f q_{i-1, t-3}$, $g q_{i, t-4}+h q_{i-1, t-4}+j q_{i, t-5}+k q_{i-1, t-5}+l q_{i-1, t-6}+m q_{i-2, t-6}$

$a=0.925, \quad b=0.075, \quad c=0.75, \quad d=0.25, \quad e=0.55, \quad f=0.45, \quad g=0.35, \quad h=0.65, \quad j=0.15$, $\mathrm{k}=0.85, \mathrm{l}=0.95$ and $\mathrm{m}=0.05$.

(d) The number of births averted was estimated by applying potential fertility estimate of 0.332 for women of $30-34$ years of age. This was selected under the assumption of mean age of use of 34 years. The number of births averted through sterilization was discarded as the mean age of acceptors was 38 years.

The demographic impact of sterilization at this subfecund stage of reproductive span was considered to be negligible.

The overestimation of the births averted by programme efforts casts doubts on the reliability of service statistics. It emerges that the programme formula for estimating the acceptors from the service statistics seems to be inappropriate in the context of Pakistan. In the case of the IUDs, the programme statistics provide information on first insertions only. The estimates of an effective use of the IUDs are affected not only by retention rates but also by such factors as fecundity, mortality, marital dissolution, amenorrhoea' and accidental pregnancies. These factors in the context of Pakistan have not been taken into account by the service statistics [5]. The non-availability of the information on these factors is bound to result in an overestimation of the number of births averted by the IUDs.

\section{SUMMARY AND CONCLUSION}

The results of the decomposition analysis of fertility changes between 1963-65 and 1976-78 show that changes in marital status contributed about 47 percent of the change in fertility whereas marital fertility contributed about 38 percent of such a change. The contributions of age structure and the proportion of females to fertility change were 10 percent and 18 percent respectively. Since the decline in marital fertility was due to both the programme and non-programme effects, it was considered desirable to estimate the contribution of the programme effect as well. The total number of the births averted in 1978 was estimated through decomposition analysis on the assumption of constant fertility throughout the reference period. The births averted by the programme method were arrived at by applying the Lee \& Isbister [4], Mauldin [5] and Wishik \& Chen [13] techniques to programme statistics. It was observed that the programme statistics showed a 41 -percent overestimation of the births averted through programme efforts as compared to the observed number of births averted by changes in marital fertility. The overestimation of births by programme statistics is probably due to measurement problems, such as those which arise from an overemphasis on the distribution of conventional methods to sales agents and their subsequent conversion into effective users. Moreover, the information on the IUDs is for first insertions only and does not include information on fecundity, mortality, marital dissolution, amenorrhoea, and accidental pregnancies of the acceptors.

It was, however, observed that the decline in fertility due to changes in marital status and marital fertility was consistent with the demographic changes taking place in Pakistan prior to 1978. The data sets from the PGE and the PGS suffered from sampling and non-sampling errors as well as from the incidence of age misreporting.

The study, however, indicates that there is a dire need of ensuring consistency in service statistics of the family planning programme, so that the impact of the programme on fertility levels may be measured with reasonable accuracy. It may be suggested that the contraceptive methods directly provided to acceptors through the programme personnel or clinics, especially conventional methods and oral pills, should be recorded separately from those distributed in the market. The quality of data needs to be considerably improved before any pragmatic policy recommendations can be offered. 


\section{Appendix Table 1}

A. Age Structure, Marital Fertility, Proportion Married and Other Demographic Measures: Pakistan Population Growth Estimation Experiment (PGE) 1963-65

\begin{tabular}{lccc}
\hline Age & ASMFR & Age Structure & Proportion Married \\
\hline $15-19$ & 400 & $24.179 *$ & $37.362 *$ \\
$20-24$ & 323 & 20.007 & 84.480 \\
$25-29$ & 350 & 16.375 & 91.320 \\
$30-34$ & 332 & 13.304 & 94.682 \\
$35-39$ & 233 & 10.738 & 92.537 \\
$40-44$ & 110 & 8.598 & 86.201 \\
$45-49$ & 67 & 6.797 & 80.335 \\
Observed 1963-65 (LR+CD) CBR $=46.46$ & \\
Proportion women 15-49 years of age in total population $=0.21183$ \\
\hline Source: [2] \\
*Adjusted rates
\end{tabular}

B. Age Structure, Marital Fertility, Proportion Married and Other Demographic Measures: Pakistan Population Growth Survey (PGS) 1976-78

\begin{tabular}{lccc}
\hline \multicolumn{4}{c}{$1976-78$} \\
\hline Age & ASMFR & Age Structure & Proportion Married \\
\hline $15-19$ & 202 & 20.625 & 26.211 \\
$20-24$ & 351 & 18.054 & 75.315 \\
$25-29$ & 362 & 15.567 & 91.701 \\
$30-34$ & 304 & 14.357 & 94.784 \\
$35-39$ & 232 & 11.802 & 94.794 \\
$40-44$ & 144 & 10.305 & 91.950 \\
$45-49$ & 60 & 9.141 & 89.180 \\
Observed PGS 1976-78 CBR $=41.433$ & & \\
Proportion women $15-49$ years of age in total population $=0.20780$
\end{tabular}

\section{REFERENCES}

1. Coale, Ansley J. "Constructing the Age Distribution of a Population Recently Subject to Declining Mortality”. Population Index. Vol. 37, No. 2. 1971.

2. Farooqui, M.N.I., and Ghazi M. Farooq. Final Report of the Population Growth Estimation Experiment 1962-65. Dacca: Pakistan Institute of Development Economics. 1971

3. Kitawaga, E M. "Components of a Difference between Two Rates". Journal of the American Statistical Association. Vol. 50. 1955.

4. Lee, B.M., and John Isbister. "The Impact of Birth Control Programmes on Fertility". In Bernard Berdson et al. (eds.), Family Planning and Population Programmes: A Review of World Development. Chicago: University of Chicago Press. 1966.

5. Mauldin, Parker W., Dorothy Nortman and Frederick F. Stephen. "Retentiơn of IUDs: An International Comparison”. Siudies in Family Planning. No. 18 1967.

6. Pakistan. Census Organization. Census of Pakıtan, 1951: (West Pakistan). Karachi. n.d.

7. Pakistan. Census Organization. Census of Pakistan, 1961: (West Pakistan) Karachi.n.d.

8. Pakistan. Census Organization. Census of Pakistan, 1972: Islamabad. 1973.

9. Pakistan. Population Census Organization. Census of Pakistan: 1981. Islamabad. 1981.

10. Pakistan. Population Welfare Division. Report on the Working of Pakistan's Family Planning Programme, 1965-78. Islamabad.

11. Pakistan. Statistics Division. Federal Bureau of Statistics. Population Growth Survey. Karachi. 1976, 1977 and 1978.

12. Retherford, Robert D., and G. Mujtaba Mirza. Evidence of Age Exaggeration in Demographic Estimates for Pakistan. Honolulu. East-West Center. 1981 (East-West Population Institute Working Paper No. 10)

13. Wishik, Samuel M., and K.H. Chen. "Couple Years of Protection: A Measure of Family Planning Programme Output”. In Family Planning and Population Programmes: Manual No. 7. New York: International Institute for the Study of Human Reproduction, Columbia University. 1973. 


\section{Comments on}

\section{"An Analysis of Fertility Change in Pakistan"}

The authors have correctly highlighted the problems created in all walks of national life by the population explosion of the last three decades in Pakistan when the population growth rate increased from 1 percent to 2 percent in the pre-1951 period and to almost 3 percent in the post-1951 period. This increase, as pointed out by the authors, has been brought about by a rapid decline in mortality rates. The upsurge has taken place despite some fall in fertility and the authors have attempted to quantify the factors which have led to the decline in the Crude Birth Rate (CBR) and the General Fertility Rate (GFR).

The authors have correctly pointed out the poor quality of the data which they had to deal with. Both Population Growth Estimation (PGE) and Population Growth Survey (PGS) Phase-II suffer from sampling and non-sampling errors. Besides the endemic problem of age reporting, there was deterioration in the quality of data in a survey like PGE which was conducted over a period of three years.

For the 1962-65 period, the authors have taken an average of Cross-Sectional (CS) and Chandra-Deming (CD) estimates of the PGE. These were 39 and 53 respectively. In my opinion, the authors have created an artifact CBR figure of 46 by taking an average of these highly divergent estimates. If the authors really believe in averaging estimates of different methodologies they should have taken the average of LR, CS and CD estimates which would have given them a lower average figure of 44 as the PGE (1962-65) had a third estimate based on Longitudinal Registration (LR). According to this estimate, the CBR was 42 , which in my opinion was closest to reality. Taking of an average of two different methodologies of sampling should be avoided as the CD estimate of 53 was a deviant one and in fact no serious demographer can uphold this high figure for a large population group like Pakistan. Therefore, in my opinion the authors should have eliminated the CD (Chandra-Deming) estimate and worked on the LR estimate of 42 . But, unfortunately, in that case the authors would have nothing to prove or disprove as the average birth rate of the PGS-II is 41.4. Probably the fertility rate in Pakistan has fallen very little although it may not have fallen as little as indicated by these two figures. The authors could have done better if, instead of using the averages of CD and LR estimates, they had used only the average of the LR estimate for 1962-65 as benchmark. Also, they should have considered the fertility rates yielded by the recent Population, Labour Force and Migration Survey (PLM) in place of the 1976-78 PGS rates. 
The other comment on the quality of data concerns the effect of sampling variation in the two sets of the data based on different types of samples. For example, in the PGE it was a cluster sample whereas in the PGS a systematic sampling technique was used.

I have also compared the age structure and marital status data used in the paper with those of the 1981 Census. Of course, there were problems with the age data obtained in the 1981 Census, but these data are more recent and are based on a total count rather than on a sample. The difference between the PGS and the 1981 Census in respect of the percentage of female population is more significant in the older age groups of $30-34$ and above. In respect of married females, the difference between the two sets of data (Census and PGS) is more significant in almost all age groups, and it is particularly notable in the younger age groups of 15-19 and $20-24$.

The authors have explained the fall in fertility by quantifying the contribution of age structure, marital status and marital fertility. It would have been better if they had eliminated age structure altogether as age reporting is extremely poor in all surveys and its contribution, even according to their analysis, is marginal (explaining only 10 percent). They have correctly concluded that marital status (age at marriage) has been a more important factor than marital fertility in the decline of the CBR and the GFR. The authors have correctly emphasized the very limited impact of the family planning programme and cast serious doubts on the reliability of the service statistics. They have also correctly pointed out that in the context of Pakistan, it is wrong to base estimates on the initial acceptance of a service. For example, in the case of the intra-uterine device (IUD) programme, the service statistics provide information on first insertions only, whereas the effective use of the IUD is influenced not only by the retention rate but also by factors like fecundity, marital status, marital dissolution, etc. They have correctly emphasized the need for more up-to-date and scientific service statistics for determining the role of the Family Planning Programme in bringing down the birth rate.

However, I wish to congratulate both the authors, Mr. Farooqui and $\mathrm{Mr}$. Soomro, on undertaking this valuable exercise. The authors have highlighted the gap in information on fertility trends in Pakistan and the need for more a reliable data collection for assessing the behaviour of the CBR and the GFR. They have correctly concluded that to date the impact of family planning has been insignificant and the major contributor to a decline in fertility has been the increase in the age at marriage. The authors' message of adverse impact of high CBR in different walks of national life and the dire need of an effective population policy to bring about a sharp reduction in that rate needs to be taken to every Pakistani home. 